\title{
The Sep1 strand exchange protein from Saccharomyces cerevisiae promotes a paranemic joint between homologous DNA molecules
}

\author{
Junghuei Chen, Roland Kanaar, and Nicholas R. Cozzarelli ${ }^{1}$ \\ Department of Molecular and Cell Biology, University of California, Berkeley California 94720 USA
}

Strand exchange protein 1 (Sep1) from the yeast Saccharomyces cerevisiae promotes the transfer of one strand of a linear duplex DNA to a homologous single-stranded DNA circle. Using a nitrocellulose filter binding assay and electron microscopy, we find that Sep1 promotes the pairing of homologous DNA molecules via a paranemic joint. In this joint there is no net interwinding of the parental DNA molecules, as in the standard plectonemic double helix. The paranemic joints form with as little as 41 bp of homology between the parental DNA molecules. The substrates used were a circular molecule (either single-stranded DNA or duplex supercoiled DNA) and a linear duplex with heterologous regions at both ends to bar duplex plectonemic intertwining. We excluded the possibility that the exonuclease activity of Sep1 exposes complementary single-stranded regions that constitute the joint. The paranemic joint is the key intermediate in the search for homologous DNA by the RecA protein of Escherichia coli. Our results imply that the search process in a eukaryote such as yeast can be mechanistically similar.

[Key Words: General recombination; yeast; RecA; homologous pairing]

Received February 10, 1994; revised version accepted April 27, 1994.

The essential events in the homologous recombination of DNA are the synapsis, or apposition, of like sequences and the subsequent exchange of DNA between the parental molecules. Synapsis is the more challenging step because the efficiency of recombination depends on rapid and faithful pairing in the face of a vast excess of heterologous pairwise comparisons. In site-specific recombination, synapsis is brought about by the binding of a recombinase to each of a pair of specific sequences and the dimerization of the recombinase (Stark et al. 1992; Sadowski 1993). The synaptic complex is thus held together by the strong and specific forces of DNA-protein interactions and protein-protein interactions.

General recombination does not have the luxury of such a simple scheme, because the putative recombinase would have the conflicting demands of generality and specificity of binding. The only force known that reconciles these demands is hydrogen bonding between complementary bases. In general recombination, DNA-DNA interactions must replace the protein-DNA and proteinprotein interactions in site-specific recombination.

Although base sequence complementarity can, in principle, solve the specific recognition problem of general recombination, formidable kinetic problems remain.

${ }^{1}$ Corresponding author.
General recombination requires only a short region of sequence homology, on the order of 100 nucleotides. Thus, the number of such lengths is only a little less than the total number of base pairs in a genome. Even if some process generates a single-stranded region in one parent, it would take too long to search for homology in the other parent by sequential cycles of denaturation and attempted reannealing of candidate sequences.

The complete resolution of this difficulty is not known, but critical factors are probably the involvement of recombination proteins in the search for homology and the subdivision of the search into more manageable steps. A particularly informative model reaction for a portion of general recombination has been the transfer of one strand of a linear duplex DNA to a single-stranded DNA circle (Fig. 1). The product is a nicked circle with one strand from each parental DNA. The formation of such a heteroduplex could provide a committed step to recombination in which the search for homology has been concluded successfully.

Proteins capable of catalyzing the single-strand transfer reaction have been purified from numerous sources, but the RecA protein of Escherichia coli is the archetype and prototype (Kowalczykowski 1991; Kowalczykowski and Eggleston 1994; Radding 1991; Camerini-Otero and Hsieh 1993; Cox 1993). The critical role of RecA is attested to by the $10^{4}$-fold drop in conjugative recombina- 
A

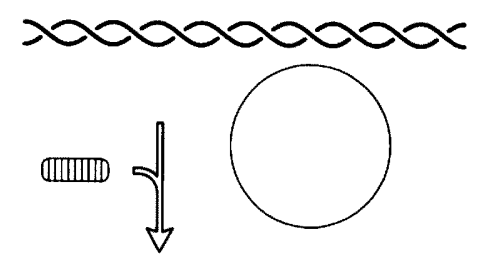

B
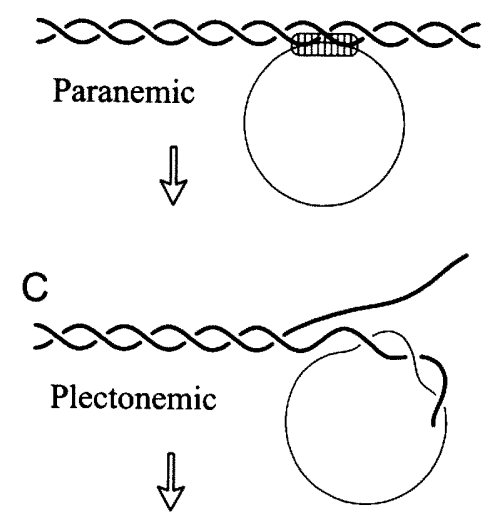

D

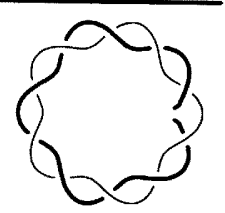

Figure 1. Strand transfer via paranemic and plectonemic joint intermediates. (A) A duplex DNA (bold lines), a single-stranded circular DNA with the same sequence (thin line), and a strand transfer protein (vertically hatched oblong) are indicated. $(B) \mathrm{A}$ paranemic joint is formed. There is no net intertwining between the paired DNA molecules, but homologous sequences are juxtaposed. $(C)$ A plectonemic joint is formed. A paranemic joint greatly increases the concentration of sequences in the singlestranded circular DNA that are homologous to the sequence near the end of the linear duplex DNA, thereby promoting the formation of a plectonemic joint in which the paired DNAs are intertwined. For simplicity, neither the strand transfer protein nor a paranemic joint is indicated. $(D)$ The terminal heteroduplex of the plectonemic joint is extended by branch migration until a heteroduplex nicked circular DNA and a single-stranded linear DNA are generated.

tion in rec $A^{-}$cells (Clark and Margulies 1965). In vitro RecA protein binds preferentially to single-stranded DNA and forms an extensive nucleoprotein filament at the expense of ATP. This filament is the active species in the search for homology in a duplex DNA partner.

A key intermediate in this search is a molecule in which donor and recipient DNA are synapsed via a paranemic joint (DasGupta and Radding 1982; Bianchi et al. 1983; Adzuma 1992) (Fig. 1B). The joint is called paranemic because there is no net intertwining of the paired DNA molecules, as in the standard plectonemic DNA double helix. A RecA-mediated paranemic joint can be formed between closed circular single-stranded and duplex DNA molecules where the linking number between the circles must be zero /Cunningham et al. 1980). For most experiments, however, it is more convenient to use a linear duplex DNA containing a region of homology to a circular single-stranded partner bounded by heterology. The terminal heterology bars the formation of a plectonemic duplex in the homologous region.

As a consequence of the absence of net strand intertwining, the paranemic joint is unstable once the RecA protein is removed and probably includes non-WatsonCrick base pairs (Camerini-Otero and Hsieh 1993; Rao and Radding 1993). The paranemic joint should accelerate recombination by greatly increasing the local concentration of the homologous sequences that exchange. It has been demonstrated (Riddles and Lehman 1985) that the paranemic joint is formed more rapidly than the next intermediate in recombination, in which the donor molecules are synapsed via a plectonemic joint (Fig. 1C).

Formation of the plectonemic joint requires a DNA end in a homologous region to initiate intertwining. After the plectonemic joint is formed, branch migration can complete the formation of a heteroduplex DNA molecule (Fig. 1D). Branch migration with DNA alone can form a heteroduplex via a random walk. RecA facilitates heteroduplex formation by making migration unidirectional (Cox and Lehman 1981; Kahn et al. 1981; West et al. 1981). The energetic cost of unidirectionality is paid for by the hydrolysis of ATP. The RecA-mediated rate of branch migration of $2-10 \mathrm{bp} / \mathrm{sec}$ is still relatively slow, but the fork can traverse great distances and pass through long heterologous insertions (Bianchi and Radding 1983).

Intermediates in the search for homology have not been extensively characterized in eukaryotes, and that is the subject of this report. Eukaryotic proteins implicated in general recombination have been best studied in the yeast Saccharomyces cerevisiae. One class of yeast proteins, which includes Rad51, DMC1, and Rad57, shares sequence similarity with RecA (Bishop et al. 1992; Shinohara et al. 1992; Story et al. 1993). Rad51 binds DNA in an ATP-stimulated fashion (Shinohara et al. 1992), and the helical structure of the resulting nucleoprotein filament is remarkably like that formed by RecA (Ogawa et al. 1993). Although there is good genetic evidence for a role of these RecA sequence analogs in meiotic recombination (Bishop et al. 1992; Shinohara et al. 1992), there is as yet no biochemical evidence that these proteins carry out strand transfer or any reaction implicated in recombination.

Another class of proteins from a large number of eukaryotic species has been shown to carry out strand transfer in vitro (Kolodner et al. 1987; Sugino et al. 1988; Halbrook and McEntee 1989; Lowenhaupt et al. 1989; Fishel et al. 1990 ). These proteins have no amino acid sequence similarity to members of the RecA family, do not hydrolyze ATP, and form no discernible nucleoprotein filaments. The strand transfer proteins are better characterized biochemically than the eukaryotic RecA sequence homologs, but compelling genetic evidence for a role in recombination is absent. 
The strand exchange protein 1 (Sepl, a.k.a. STP $\beta$ ) from yeast is the best studied of the eukaryotic strand transfer proteins (Kolodner et al. 1987; Dykstra et al. 1990; Kim et al. 1990; Johnson and Kolodner 1991). Sepl is a large protein with a molecular weight of $\sim 175,000$. It has been purified to homogeneity, and its gene has been cloned, sequenced, and mapped (Larimer and Stevens 1990; Dykstra et al. 1991; Kersey and Kipling 1991; Tishkoff et al. 1991). Sep1 not only promotes strand transfer, as diagramed in Figure 1, but also the renaturation of homologous single-stranded DNA molecules (Heyer et al. 1988). RecA has a similar annealing activity (Weinstock et al. 1979). Johnson and Kolodner (1991) have shown that in addition to these activities, Sepl contains an intrinsic $5^{\prime} \rightarrow 3^{\prime}$ exonuclease activity, which exposes a terminal single-stranded region in duplex linear DNA. They have found that such a region is necessary for strand transfer.

Sep1 mutants have a complex phenotype and have been obtained in strikingly different ways (for review, see Kersey and Kipling 1991). They were isolated as knockouts of the gene encoding a DNA strand transfer protein (Dykstra et al. 1990; Tishkoff et al. 1991) and as a knockout of a gene that encodes a major exoribonuclease (Stevens and Maupin 1987). Sepl mutants were also identified on the basis of their reduction of nuclear fusion (Kim et al. 1990) and the potentiation of the replication of plasmids with weak autonomously replicating sequences (ARSs) (Kipling et al. 1991). Mitotic recombination has been reported to be reduced fivefold in Sepl mutants (Dykstra et al. 1991; Tishkoff et al. 1991). Because the protein is large and already known to carry out two very different reactions in vitro /strand transfer and exonuclease), multifunctionality may contribute to this pleiotropism. This is clearly the case for RecA, which is also a coprotease (Little and Mount 1982).

In this paper we establish that Sepl efficiently forms a paranemic joint. The joint can be formed between two DNA molecules sharing only 41 bp of homology, between a single-stranded and a double-stranded DNA or even between two DNA duplexes. We have excluded the possibility that the exonuclease activity of Sepl exposes complementary single-stranded DNA regions that compose the joint. Our results implicate Sep1 in general recombination because of the importance of the paranemic joint in the search for homology. They also imply that eukaryotic and prokaryotic strand transfer proteins may use similar intermediates in the search.

\section{Results}

Sep1 forms a paranemic joint between a single- and a double-stranded DNA

A simple yet quantitative assay for the formation of a paranemic joint that has been used extensively in studies of RecA protein involves the binding of DNA to a nitrocellulose filter (Riddles and Lehman 1985). After pretreatment with a high concentration of $\mathrm{NaCl}$, single- stranded DNA adsorbs to this material but duplex DNA does not. If ${ }^{3} \mathrm{H}$-labeled duplex DNA is mixed with a homologous unlabeled single-stranded DNA and Sepl, ${ }^{3} \mathrm{H}$ label is retained by the filter only if a joint molecule is formed between the two DNAs. The pair of DNA molecules that we used to insure that a paranemic joint is detected is diagramed at the top left of Figure 2. The single-stranded DNA is circular phage M13mp18 DNA (hereafter referred to as M13) and the linear duplex DNA is XhoI digested ${ }^{3} \mathrm{H}$-labeled M13Gori 1 (hereafter referred to as MGori I). In the latter DNA, the middle $6.4 \mathrm{~kb}$ of M13 sequences is surrounded by 1.0 and $1.2 \mathrm{~kb}$ sequences with no relation to M13. The identical, or homologous, sequences are shown as a thin line in this and subsequent figures, and the different, or heterologous, sequences are shown as a thick line. The terminal heterologies in the linear DNA prevent the formation of a standard plectonemic joint, and their large size blocks the weak exonuclease of Sep1 from digesting past them during the course of the experiments.

Within minutes at $37^{\circ} \mathrm{C}$, Sepl mediates the joining of one-third of the linear duplexes to the single-stranded M13 DNA (Fig. 2A). The joint is homology dependent, because no joint molecules were detected when the single-stranded M13 DNA was replaced by $\phi$ X174 singlestranded DNA (hereafter referred to as $\phi \mathrm{X}$ DNA). The joint was abolished by treatment with $5.2 \mathrm{M}$ guanidine hydrochloride, which demonstrates the need for the continued presence of Sepl. The paranemic joint formed by RecA has the same sensitivity to this protein denaturant (Riddles and Lehman 1985). Similar results were obtained with a moderately reduced amount of Sepl and the yeast DNA-binding protein II (DBP II) (Fig. 2C). This protein spares the requirement in strand transfer for Sepl and for another yeast DNA exchange protein, STP $\alpha(\mathrm{Ha}-$ matake et al. 1989; A. Sugino, unpubl.).

We measured the promotion of a plectonemic joint by Sepl using the pair of DNA molecules diagramed at the top right of Figure 2. In this case, the homologous M13 sequences $(3.0$ and $3.4 \mathrm{~kb})$ are at the ends of the linear duplex DNA and the heterologous sequence is in the middle. With these substrates, $85 \%$ of the linear duplex DNAs form joint molecules (Fig. 2B). Similar results were again found in the presence of DBP II and less Sep1 (Fig. 2D). In contrast to the results with the paranemically joined molecules, one-third to two-thirds of the plectonemically joined molecules survived exposure to $5.2 \mathrm{M}$ guanidine hydrochloride (Fig. 2B,D). Presumably, the disrupted joints were either paranemic or plectonemic but dissociated via branch migration. The plectonemic joint was homology dependent because replacement of single-stranded M13 DNA with single-stranded $\phi \mathrm{X}$ DNA led to no significant formation of joint molecules.

\section{Electron microscopy of Sep1-mediated paranemic joints between single- and double-stranded DNAs}

The filter-binding assay is rapid and quantitative, but electron microscopy is needed to observe the position 


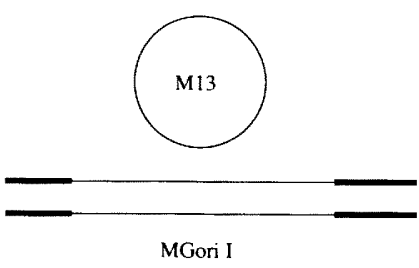

(A)

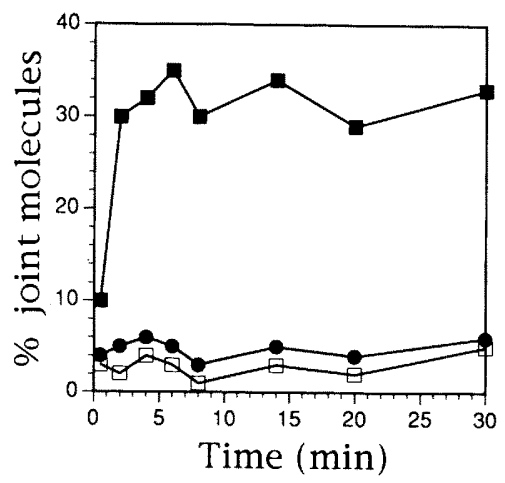

(C)

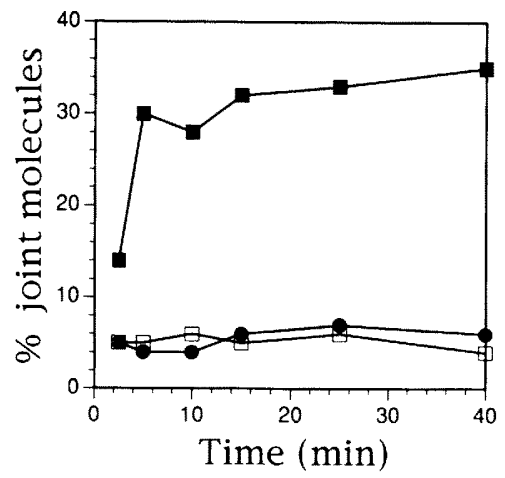

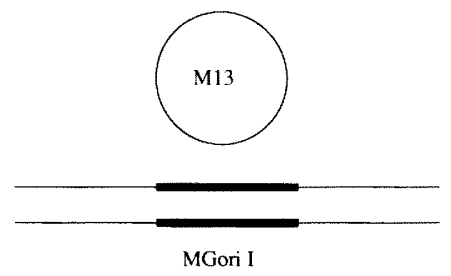

(B)

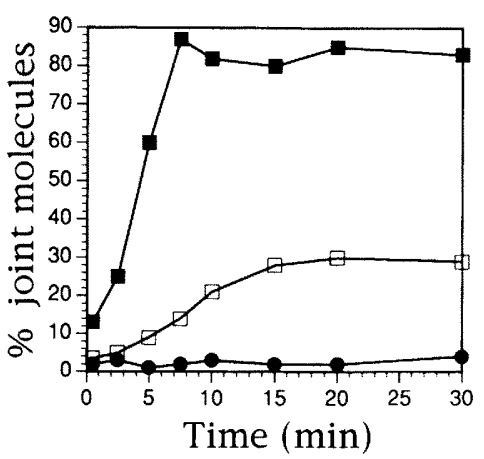

(D)

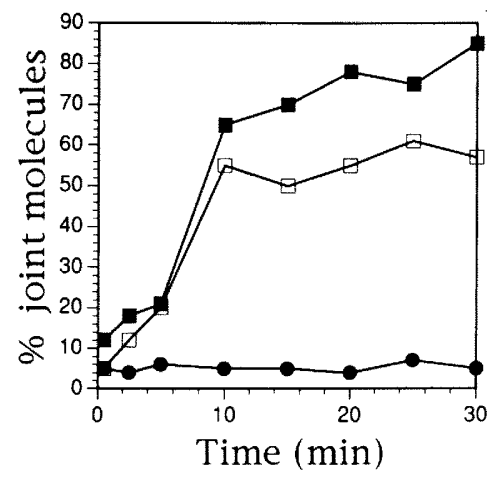

Figure 2. Detection of Sepl-mediated paranemic and plectonemic joints between homologous DNA molecules by nitrocellulose filter binding. Quantities of 0.07 pmole of a ${ }^{3} \mathrm{H}$-labeled linear duplex DNA (MGori I) and 0.07 pmole of single-stranded circular DNA (M13) were mixed with either 14 pmoles of Sepl $(A, B)$ or 7 pmoles of Sep1 plus 30 pmoles of DBP II $(C, D)$, the yeast DNA-binding protein. The mixture was then passed through a nitrocellulose filter, which retains only single-stranded DNA. Thus, ${ }^{3} \mathrm{H}$-labeled DNA is retained only if a joint is formed between the single-stranded and duplex DNA molecules. The reaction mixtures were either added directly to the filter $(\square)$ or were treated first with $5.2 \mathrm{M}$ guanidine hydrochloride at $37^{\circ} \mathrm{C}$ for 10 min to denature proteins (ㅁ) . In the control reactions (O), M13 single-stranded DNA was replaced by $\phi \mathrm{X}$ single-stranded DNA, which has no sequence homology to the ${ }^{3} \mathrm{H}$-labeled duplex DNA. $(A, C)$ Paranemic joint formation. Both ends generated by XhoI digestion of the ${ }^{3} \mathrm{H}$-labeled duplex MGori I DNA are heterologous to M13 circular singlestranded DNA, diagramed at top left. The thin and thick lines refer to homologous and heterologous regions, respectively. $(B, D)$ Plectonemic joint formation. Both ends generated by $\mathrm{BamHI}$ digestion of the ${ }^{3} \mathrm{H}$-labeled duplex MGori I DNA are homologous to the M13 circular single-stranded DNA, diagramed at top right. and extent of the joints. The DNA molecules examined were the same ones analyzed by filter binding, namely M13 single-stranded DNA and linear duplex MGori I DNA (see diagram, Fig. 3, top). We chose to examine joint molecules formed after only $3 \mathrm{~min}$ to reduce the multimerization of the DNAs. The DNA was spread out by binding to a cytochrome $c$ film and viewed without addition of a protein-cross-linking agent such as glutaraldehyde. About $70-80 \%$ of the DNA molecules were in oligomeric forms, which were difficult to interpret. The remainder were mostly dimers containing either one molecule of circular single-stranded M13 DNA and one molecule of the linear duplex DNA or two linear duplex DNAs. We saw no oligomers containing only singlestranded DNA circles and very few monomers of either DNA. Examples of joints between the circular and linear DNAs are shown in Figure 3 . The single-stranded DNA could often be distinguished from the duplex by its crinkly form, and its circularity was unmistakable. The two molecules were usually joined at only one place. The extent of the joint ranged from 100 to $1000 \mathrm{bp}$, and the majority were $\sim 200-300$ bp in length.
The distribution in the position of the joint measured from the nearest end of the duplex DNA is plotted in Figure 3. The pattern is remarkably uniform except for the absence of joints in the first $10 \%$ of the duplex DNA, the region of heterology. These results suggest that the paranemic joint requires sequence homology but has no obvious sequence preference.

\section{Minimum homology requirement for paranemic joint formation}

To provide a more stringent test of the homology requirement of the paranemic joint, we limited the homology in the linear duplex DNA parent to just $41 \mathrm{bp}$ of a $\phi \mathrm{X}$ sequence. As diagramed in Figure 4A, we positioned the $41 \mathrm{bp}$ only $20 \mathrm{bp}$ from one end of the molecule. If the intrinsic $5^{\prime} \rightarrow 3^{\prime}$ exonuclease of Sepl were to digest the linear duplex DNA, it would remove the strand that is complementary to the single-stranded $\phi X$. Thus, if a joint is observed, it cannot have resulted from exonuclease resection of the duplex and annealing to the single-stranded circular DNA. Using electron microscopy, 

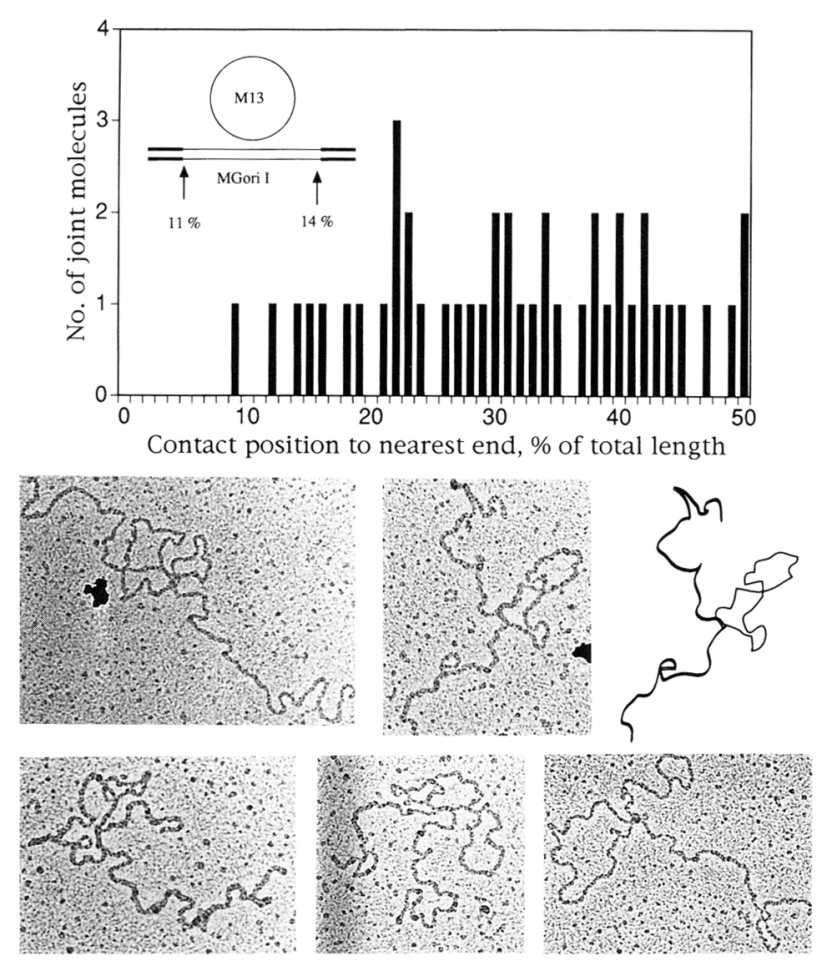

Figure 3. Detection of Sepl-mediated paranemic joints by electron microscopy. MGori I DNA was cleaved by XhoI restriction endonuclease to generate a linear duplex DNA with a 6.4$\mathrm{kb}$ region that is identical to circular single-stranded M13 DNA and that is bordered by 1.0 and $1.2 \mathrm{~kb}$ of heterologous sequences (see diagram, top left). Duplex DNA (0.07 pmole) was mixed with single-stranded DNA (0.07 pmole) in the presence of 14 pmoles of Sepl. After $3 \mathrm{~min}$ at $37^{\circ} \mathrm{C}$, the molecules were spread for electron microscopy by a cytochrome $c$-formamide method. Electron micrographs of examples of joint molecules are shown. A schematic tracing of the molecule is shown in which the M13 circular DNA is indicated by a thin line and the MGori I duplex linear DNA by the bold line. The position of the joint in all scorable molecules is plotted in the bar diagram.

we observed that $70 \%$ of the dimeric molecules had circular single-stranded $\phi \mathrm{X}$ DNA joined to one end of the linear duplex DNA, the predicted location (Fig. 4A).

As further proof of the sequence specificity of the paranemic joint, we moved the $41 \mathrm{bp}$ of homology to one-third of the way from one end of the linear duplex DNA. We again observed joint molecules, but now $64 \%$ of the joints were located one-third of the way from the end of the linear duplex DNA, the region of homology (Fig. 4B). The two experiments in Figure 4 provide controls for each other. They also show that only $41 \mathrm{bp}$ is sufficient for formation of a paranemic joint. The DNA molecules seemed to just touch at the joints (Fig. 4). The joints were clearly shorter than those formed between more extensive regions of homology (Fig. 3).

Formation of a paranemic joint between two duplex molecules

Thus far we have demonstrated that Sepl forms a paranemic joint between a single-stranded circular DNA and a homologous region of a linear duplex DNA. This is a paradigmatic reaction for RecA, a protein that is activated by single-stranded DNA. Sep1, however, binds to duplex DNA almost as well as to single-stranded DNA (Heyer et al. 1989). Therefore, we tested whether Sepl could mediate a paranemic joint between two duplex DNAs. For these experiments, we used a supercoiled plasmid, pPiaI, and a linear duplex DNA with heterology at both ends (diagramed in Fig 5, top). Observation of a supercoiled DNA molecule at a joint ensures that the DNA has not been nicked and resected by the nuclease activity of Sep1.

Electron microscopy showed efficient joint formation between the two duplex DNA molecules. The 900-bp homologous region stretches from $4 \%$ to $16 \%$ from one end of the duplex DNA, and the attachments between the supercoiled and linear duplex DNAs were spread relatively uniformly over this interval (Fig. 5). Only a background level of joints was found elsewhere. The electron micrographs verified that the plasmid DNA part of the joint molecule is still supercoiled. Thus, the paranemic joint does not relax a supercoiled parental DNA, unlike the situation with RecA protein (Wu et al. 1983; Christiansen and Griffith 1986; Schutte and Cox 1988). The Sepl-mediated joint was sharply defined, usually a point contact. Supercoiled DNA molecules seemed about as likely to form a joint molecule with another supercoiled molecule as with linear DNA, as judged by the appearance of pPiaI oligomers. Half of the supercoiled molecules shown in Figure 5 that are joined to a linear duplex DNA are also joined to another supercoiled DNA.

To test for the stringency of the homology requirement for formation of a paranemic joint between two duplex DNA molecules, we used as one parent the duplex linear DNAs with 41 bp of homology to $\phi X$ that we used in the experiments shown in Figure 4 . The other parent was supercoiled $\phi \mathrm{X}$ DNA rather than singlestranded DNA (diagramed in Fig. 6A and B, top). Electron microscopy showed that the joints were primarily at the sites of homology. When the homology was at one end of the duplex DNA (Fig. 6A), 52\% of the joints were at this position. With the $41 \mathrm{bp}$ of homology one-third of the way in from one end (Fig. $6 \mathrm{~B}$ ), $54 \%$ of the joints were at this position. In the remainder of the joint molecules, the position of the joined supercoiled DNA was spread uniformly over the duplex DNA. Thus, the paranemic joint between duplex DNA molecules is also homology dependent. The electron micrographs indicate again that the $\phi \mathrm{X}$ DNA was still supercoiled and that the joint region is small.

\section{Discussion}

We studied the formation of homology-dependent synapsis of DNA molecules by the Sepl strand exchange protein of yeast. First, we present our major conclusions and the experimental evidence for them. Subsequently, we discuss the possible structure of the Sepl-mediated 
A
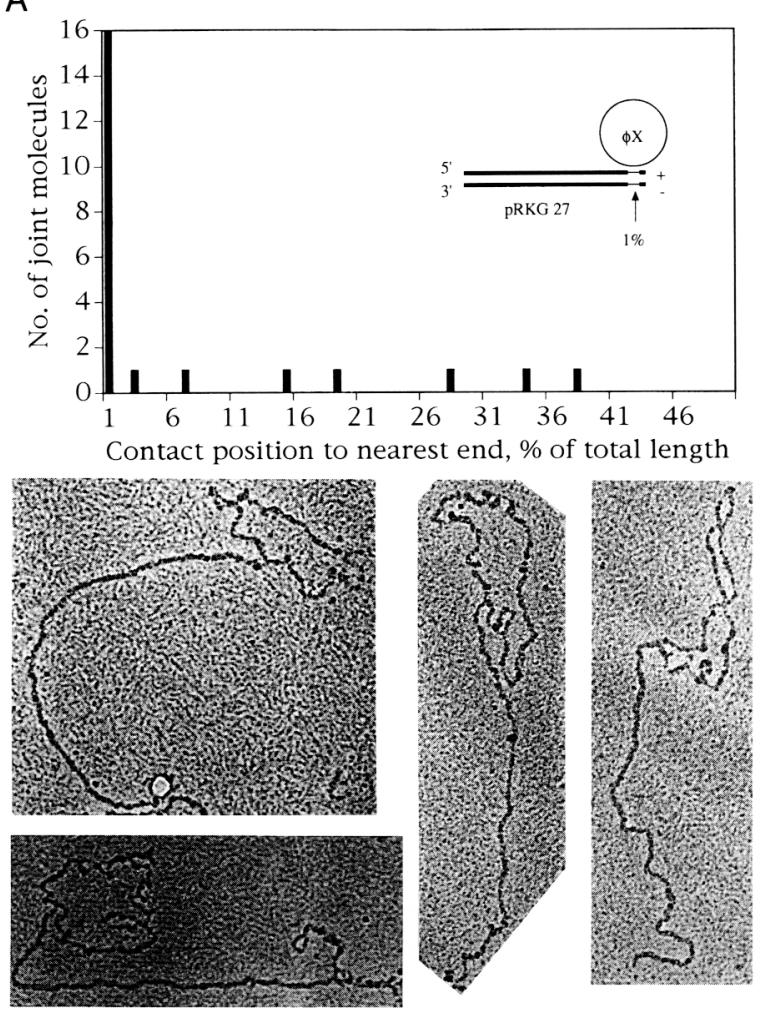

B
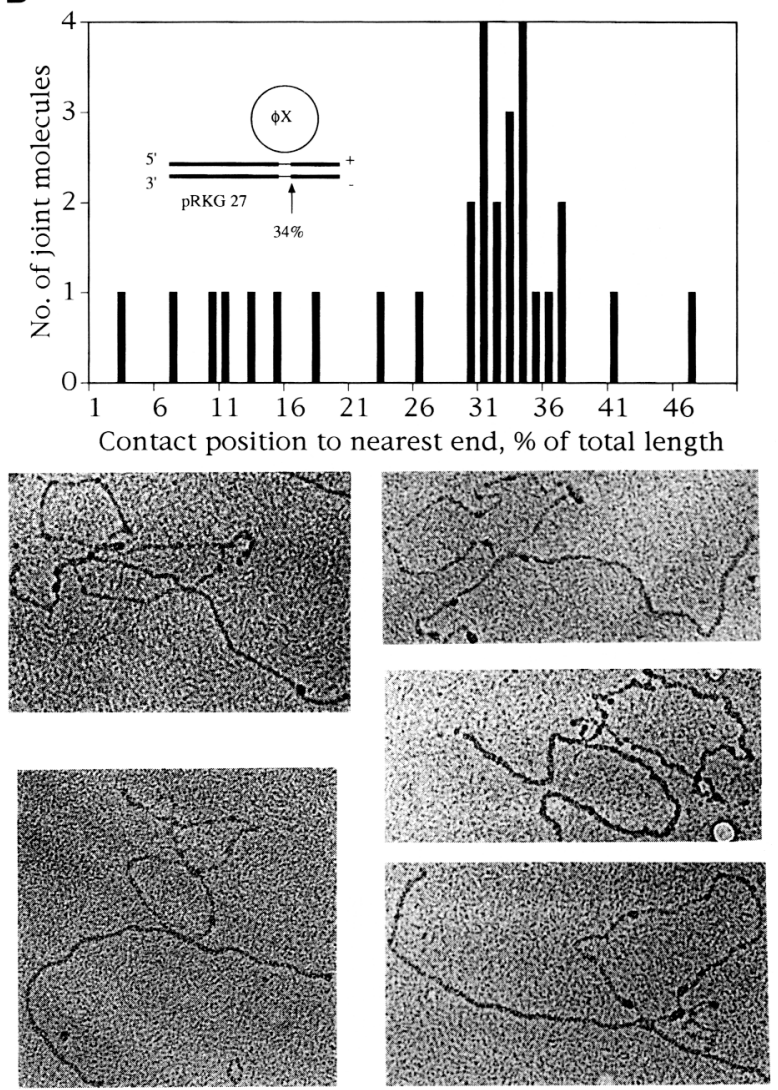

Figure 4. Sepl-mediated formation of a paranemic joint molecule between circular $\phi X$ single-stranded DNA and linear duplex DNA sharing only 41 bp of homology. The linear duplex DNA has a 41 -bp sequence that is also found in the + strand of $\phi X$ DNA. After restriction of pRKG27 with KpnI endonuclease, the homologous region is 20 bp from the $5^{\prime}$ end of the - strand of the duplex DNA (A). After restriction with ScaI endonuclease, it is $1022 \mathrm{bp}$ from the $5^{\prime}$ of the $(-\mid$ end of the duplex DNA (B). The input DNA pairs are diagramed in the inserts. If the $5^{\prime} \rightarrow 3^{\prime}$ exonuclease activity of Sepl digested the $5^{\prime}$ end of the $(-1$ strand, then the exposed single-stranded region would be the + strand, which is identical to and thus not complementary to the + circular single-stranded $\phi \mathbf{X}$ present. Electron micrographs of some of the joint molecules are shown, along with a histogram of the position of the joint along the linear duplex DNA.

paranemic joint and compare the properties of Sepl and RecA.

1. Sep1 promotes a paranemic joint between two DNA molecules. There are two pieces of evidence for this conclusion. First, electron microscopy shows that the joint is formed in a region of homology in a linear duplex that is surrounded by long stretches of heterology. Second, filter-binding experiments showed that unlike the plectonemic joint, the joint is abolished by the protein denaturing agent guanidine hydrochloride.

2. The paranemic joint forms between homologous sequences; $41 \mathrm{bp}$ of identical sequence suffice. A minimum estimate of the sequence specificity can be made from the data in Fig. 4, for which homology is limited to $41 \mathrm{bp}$. Two-thirds of the joints are in the homology region. Assuming that all joints outside the homology region are nonspecific, and normalizing for the length ratio of the heterologous and identical sequences (2987/41), there is a 150 -fold preference for a sequence-specific joint.
3. The paranemic joint does not require exonucleolytic processing by the intrinsic exonuclease activity of Sep1 to expose single-stranded DNA in the region of homology. The exonuclease activity is feeble under our conditions, and the region of homology in the paranemic joint can be kilobases from the end. Moreover, with the linear DNA substrate used in Figure $4 \mathrm{~A}, 5^{\prime} \rightarrow 3^{\prime}$ exonuclease digestion would destroy the complementary strand in the homologous region.

4. The joints form between duplex linear DNA and either single- or double-stranded closed circular DNA. We observed chains of supercoiled DNA rings by electron microscopy, but in the absence of a sequencespecific landmark, we do not know whether these complexes are homology dependent.

\section{The Sep1-mediated paranemic joint}

It is worthwhile to speculate on the possible structure of the Sep1-mediated paranemic joint. When the region of homology was large, the size of the joint between the 


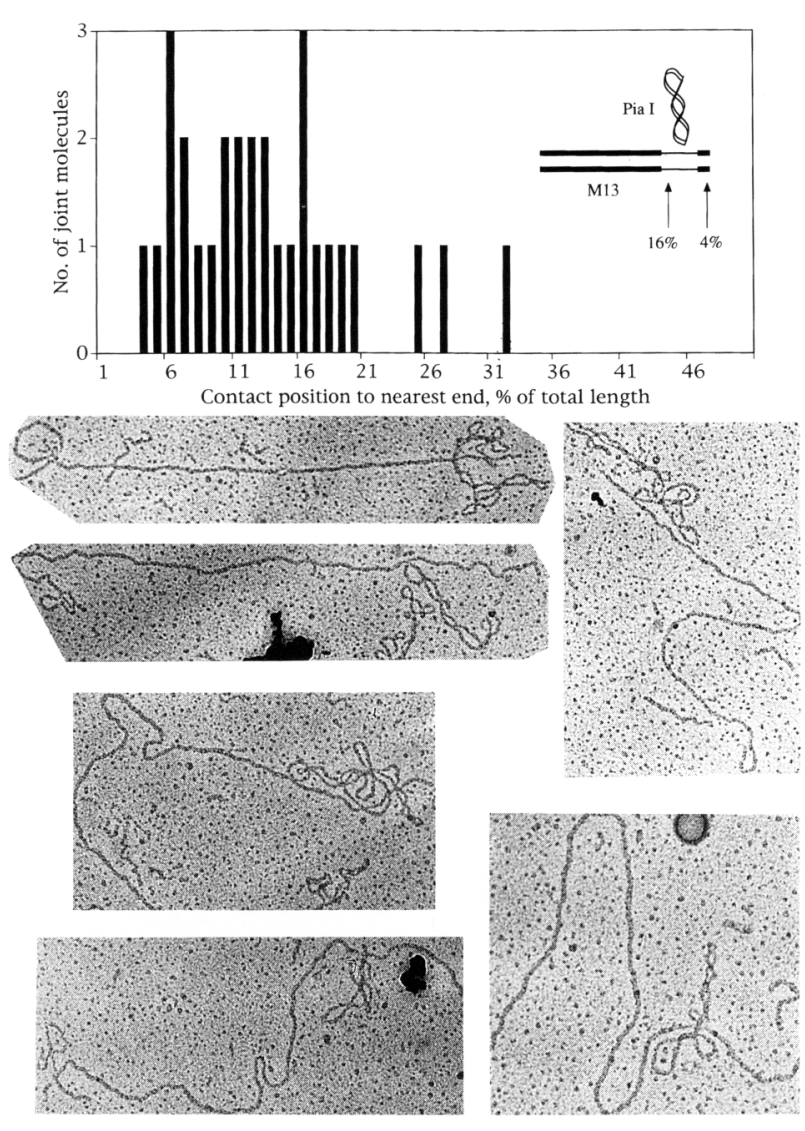

Figure 5. Sepl-mediated paranemic joints between a supercoiled plasmid DNA and a linear duplex DNA. The plasmid pPial and M13 RF DNA cut with Bglll endonuclease share 900 bp of homology. There are 300 and $6000 \mathrm{bp}$ of heterology at the ends of the linear duplex DNA (see diagramatic insert). The molecules were spread for electron microscopy. Electron micrographs of examples of the joint molecules are shown along with the distribution of the position of the supercoiled DNA along the linear DNA. Note that in three of the examples shown, a supercoiled pPial is joined both to a linear DNA and to another supercoiled pPial.

single-stranded and duplex DNAs averaged a few hundred base pairs. The extent of the joint between a supercoiled and a linear duplex DNA was even less. Because of its sequence specificity, the joint is most likely maintained by hydrogen bonds between bases on the parental DNA molecules.

The fact that the joint is paranemic strongly limits its possible structure. Consider, for example, the pair of molecules examined in Figure 5, a linear duplex DNA with $900 \mathrm{bp}$ of homology and a supercoiled plasmid. We assume that the heterologous regions flanking the region of homology in the duplex DNA do not unwind and rewind during the reaction. This seems highly likely on kinetic grounds, given the large size of the heterologous region and the lack of a requirement for ATP hydrolysis. With this assumption, the region of homology can be treated topologically as if it were a closed single-stranded circle, even though it is a linear duplex. The linking number between this virtual circle and either or both strands of the supercoiled plasmid must be zero because no DNA breakage and reunion occurs during Sep1 treatment. This condition must be met even if one end of the duplex threads through the plasmid (West 1992). Therefore, if the paranemic joint contains a plectonemic region, there must be an exact topological compensation in twist or writhe.

For example, if the paranemic joint contains a B-type DNA duplex between the complementary strands, this positive twist could be compensated by an equivalent negative writhe. However, this is unlikely on energetic grounds. The writhe must not be of either parental DNA molecule alone but of an axis between these molecules, because the twist is intermolecular. This writhing would have to be stabilized by binding to Sep1. We take the core nucleosome as our model of $(-)$ writhe stabilized by DNA-protein interactions (Richmond et al. 1984). In the nucleosome, there are $\sim 140$ bp bound per unit change in linking number. Thus, for every turn of the postulated plectonemic portion of the paranemic joint, there would have to be 140 nucleotides from each parental DNA wound in a superhelix around Sepl. This requires substantial DNA bending energy. Moreover, 130 of the 140 bp would have to be juxtaposed without the benefit of forming a plectonemic double helix. A highly organized Sepl structure would be required to direct and stabilize this rather bizarre structure, and there is no evidence for any Sepl higher-order architecture.

A B-type plectonemic region of the paranemic joint compensated by negative twist would also be energetically costly. We assume that the joint is between only one of the two strands of each duplex. The free energy of formation of such a joint would be roughly that needed to denature the 100- to 200-bp of the joint in each duplex DNA parent plus the penalty at the junction between the - and + twist regions, minus the energy gained from rewinding only half of the DNA. Without invoking a remarkable interaction with Sep1, a plectonemic joint made of left-handed and right-handed double helices also seems unlikely.

We conclude that a significant duplex plectonemic portion of a paranemic joint is unlikely because of the substantial energy needed to stabilize the compensatory twist or writhe.

A more likely alternative is a periodic bonding by sideby-side DNA molecules. Because the circular parent of the paranemic joint can be either single-stranded or double-stranded, then either the single-stranded DNA is folded between the interaction regions to maintain phasing or the duplex(es) is unwound. The hydrogen bonds between the bases that maintain the joint are probably non-Watson-Crick and must be if the duplex DNA is not unwound.

Although we have emphasized the role of DNA-DNA interactions in providing sequence specificity, Sep1 plays a continuing role in maintaining the joint. Denaturation of Sep1 by guanidine hydrochloride destroys the joint. We can imagine several possible roles for Sep1: increasing local DNA concentration; shielding repulsive 
A
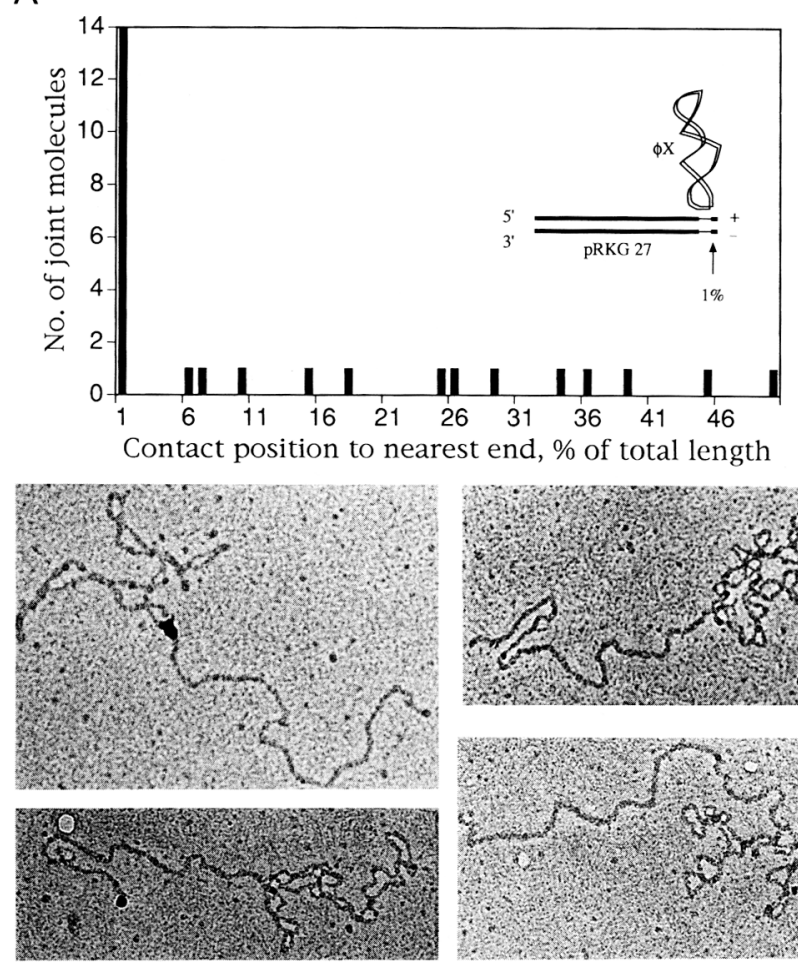

B
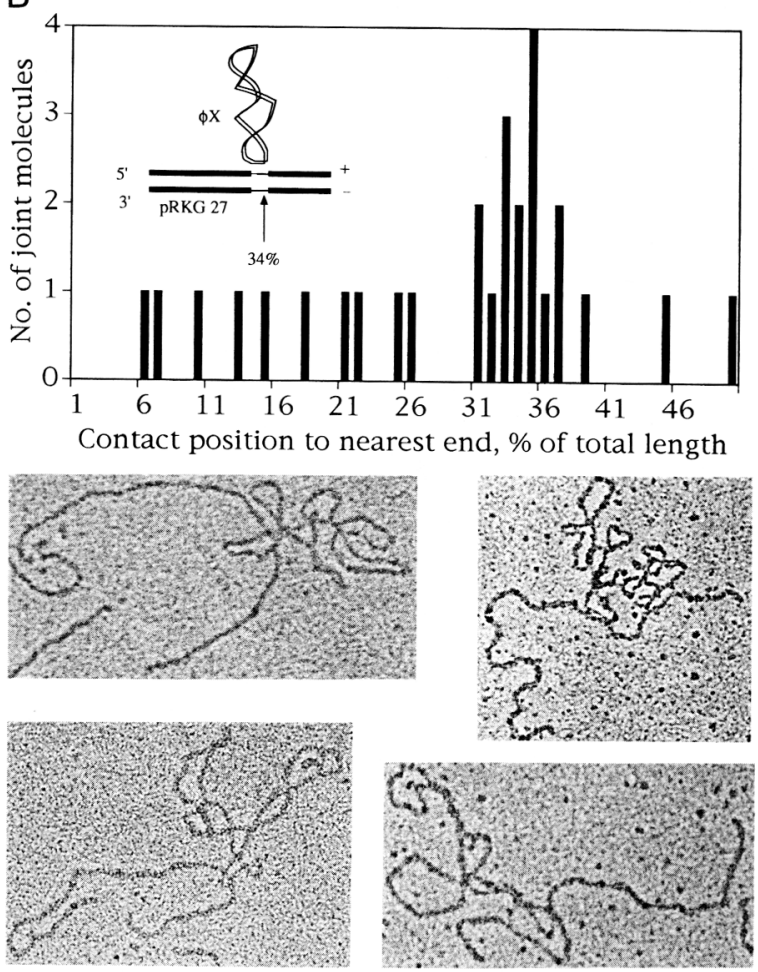

Figure 6. Sep1-mediated formation of a paranemic joint between supercoiled $\phi X$ DNA and a linear duplex DNA that shares only 41 bp of homology. The experiment was the same as that described in Fig. 4, except that supercoiled $\phi \mathrm{X}$ RF DNA was used instead of circular $\phi \mathrm{X}$ single-stranded DNA.

charge interactions between the parental backbones; and distorting the DNA into a specific structure that favors homologous non-Watson-Crick interactions (Sikorav and Church 1991).

Past experiments imply that a single-stranded end of a duplex DNA is necessary for forming a plectonemic joint by Sep1 (Johnson and Kolodner 1991). Under conditions in which the intrinsic exonuclease activity of Sepl is inhibited, a terminal single-stranded region is required. Our data show convincingly that resection of the homologous region is not necessary for a paranemic joint by Sepl.

\section{Comparisons of Sep1 and RecA}

A comparison of Sepl with RecA is instructive. Both proteins promote the formation of plectonemic and paranemic joints and bring about efficient DNA strand transfer and renaturation. They differ in that RecA forms a signature helical filament and hydrolyzes ATP during strand transfer, and in that Sepl is also an exonuclease. The differences may not be so significant. Kowalczykowski and colleagues have shown that ATP hydrolysis is not needed for strand transfer by RecA. (Menetski et al. 1990), and Cox has argued persuasively that the RecA filament has evolved for its role in repair but perhaps not in recombination (Cox 1993).

The genetic data implicating $\operatorname{RecA}$ in conjugative re- combination are impressive. Absence of the protein causes a $10^{4}$-fold drop in recombination /Clark and Margulies 1965) and a 40- to 100-fold decrease in plasmid recombination (Laban and Cohen 1981). The genetic data on Sep1 are complex and not yet convincing for a role in recombination. A fivefold drop in mitotic recombination has been observed (Dykstra et al. 1991; Tishkoff et al. 1991), but it is not clear that this is a direct effects, because Sepl mutants display a highly pleiotropic phenotype.

We believe, however, that our finding of formation of a paranemic joint by Sepl enhances the likelihood that Sepl has a role in recombination, and that the paranemic joint is an important intermediate in strand exchange. Sepl is the first eukaryotic strand transfer protein that has been demonstrated to form a paranemic joint.

\section{Materials and Methods}

\section{Proteins}

Sepl was purified as described (Dykstra et al. 1990). The final preparation was $>95 \%$ pure as judged by SDS-polyacrylamide gel electrophoresis. As reported by Johnson and Kolodner (1991), Sepl has an exonuclease activity. Under our strand exchange conditions, it is relatively weak. Incubation of 14 pmoles of Sep1 with 0.07 pmole of a $5^{\prime}{ }^{32}$ P-terminally labeled MGori I linear duplex DNA and 0.07 pmole of circular M13 singlestranded DNA released $4 \%$ of the label in $3 \mathrm{~min}$ at $37^{\circ} \mathrm{C}$, the 
incubation time used in our electron microscopy studies. With a blunt-ended linear duplex the activity was even less. No endonuclease activity was detected under the same conditions using a supercoiled substrate DNA. Restriction endonucleases $B a m H I, X h o I, S c a I, K p n I$, and BgIII were from New England Biolabs. DBP II was a gift from A. Sugino.

\section{DNA substrates}

Unlabeled circular single-stranded DNA M13mpl8 /designated $\mathrm{M} 13$ ) and $\phi \mathrm{X}$, as well as supercoiled M13 RF (replicative form) and $\phi X$ RF, were from New England Biolabs. ${ }^{3} \mathrm{H}$-labeled MGori I was prepared as described (Kaguni and Ray 1979). To minimize the amount of nicked ${ }^{3} \mathrm{H}$-labeled MGori I RF DNA, only freshly prepared DNA was used in the filter-binding experiments.

Plasmid pRKG27 is a 2987 -bp plasmid that contains 41 bp of homology to $\phi \mathrm{X}$ (nucleotide positions $3500-3540$ ). It was constructed by cloning the oligonucleotide 5'-AATTGGAGGTATATGCACAAAA-TGAGATGCTTGCTTATCAACAGA-3' and its complement with EcoRI and HindIII sticky ends, into the EcoRI and HindIII restriction sites of pBluescript $\mathrm{SK} \mid-1$ (Stratagene). Digestion of pRKG27 with KpnI generates a linear duplex DNA with the $41 \mathrm{bp}$ of homology to $\phi \times 20 \mathrm{bp}$ from one end. After digestion with Scal, the homologous region is 1022 bp from one end of the duplex DNA.

pPial is a 3656-bp plasmid that was constructed by inserting a 970-bp fragment into the EcoRI site of pUC19. There is $900 \mathrm{bp}$ of homology between pPial and M13. On the linear M13 DNA the homologous region is contiguous, but on pPial it is disrupted by the 970 -bp insertion. Digestion of the RF form of M13 $(7.2 \mathrm{~kb})$ with $B g l I I$ generates a linear duplex with the homologous region to pPial located $300 \mathrm{bp}$ from one end.

\section{Reaction conditions}

The standard reaction mixture for formation of joint molecules contained in a volume of $50 \mu \mathrm{l}, 20 \mathrm{~mm}$ Tris- $\mathrm{HCl} / \mathrm{pH} 7.9), 10 \mathrm{~mm}$ $\mathrm{MgCl}_{2}, 2 \mathrm{mM}$ dithiothreitol, $0.1 \mathrm{mg} / \mathrm{ml}$ of bovine serum albumin, 0.07 pmole of the single-stranded DNA parent, 0.07 pmole of the duplex DNA parent, and 14 pmoles of Sep1. DNA concentrations are expressed in terms of molecules and not nucleotide equivalents. In the reactions in Figure 2, C and D, only 7 pmoles of Sepl were used plus 30 pmoles of DBP II. The reactions were performed at $37^{\circ} \mathrm{C}$ for the times indicated in Figiure 2 or for $3 \mathrm{~min}$ in the experiments described in Figures 3-6.

\section{Nitrocellulose filter-binding assay}

The nitrocellulose filters (Schleicher \& Schuell, $0.45 \mu \mathrm{m}$ ) were washed extensively with distilled water and soaked in $2.0 \mathrm{M}$ $\mathrm{NaCl}$ and $0.15 \mathrm{M}$ sodium citrate at $4^{\circ} \mathrm{C}$ for at least $1 \mathrm{hr}$ before use. At the times indicated, samples $(10 \mu l)$ were withdrawn, diluted into $1 \mathrm{ml}$ of chilled $2.0 \mathrm{M} \mathrm{NaCl}$ and $0.15 \mathrm{M}$ sodium citrate, and applied to a nitrocellulose filter at room temperature. The filters were washed twice with $1 \mathrm{ml}$ of $2.0 \mathrm{M} \mathrm{NaCl}$ and $0.15 \mathrm{M}$ sodium citrate at $4^{\circ} \mathrm{C}$ and three times with $1 \mathrm{ml}$ of $0.3 \mathrm{M}$ $\mathrm{NaCl}$ and $0.02 \mathrm{M}$ sodium citrate at the same temperature. After drying for $40 \mathrm{~min}$, the amount of ${ }^{3} \mathrm{H}$-labeled duplex DNA bound to the filter was measured by a liquid scintillation spectrometer. For the treatments with guanidine hydrochloride, the samples were mixed with the denaturant and EDTA in $0.1 \mathrm{M}$ Tris- $\mathrm{HCl}$ $(\mathrm{pH} 7.5)$ to give final concentrations of $5.2 \mathrm{M}$ and $22 \mathrm{mM}$, respec- tively. After $10 \mathrm{~min}$ at room temperature, the samples were applied to a filter and processed as described above. The determinations were done in triplicate.

\section{Electron microscopy}

After forming joint molecules in a standard reaction mixture at $37^{\circ} \mathrm{C}$ for $3 \mathrm{~min}$, the mixture was diluted to a DNA concentration of $0.1-1 \mu \mathrm{g} / \mathrm{ml}$ in a spreading solution containing $30 \%$ formamide, $0.1 \mathrm{M}$ Tris- $\mathrm{HCl}(\mathrm{pH} 8.5), 0.01 \mathrm{M}$ EDTA, and 120 $\mu \mathrm{g} / \mathrm{ml}$ of cytochrome $c$. This sample was then spread over a hypophase of $10 \mathrm{~mm}$ Tris- $\mathrm{HCl}(\mathrm{pH} 8.4), 1 \mathrm{~mm}$ EDTA, and $10 \%$ formamide, picked up on parlodion grids, stained in uranyl acetate, and shadowcast with tungsten (Davis et al. 1970). Micrographs were taken with a JOEL $100 \mathrm{CX}$.

\section{Acknowledgments}

We thank Akio Sugino for teaching us the purification of Sepl in his laboratory and for providing purified DBP II. We are grateful to P. Abola for constructing pPial and K. Benjamin for performing the nuclease assays. S. Kowalczykowski reviewed the manuscript intensively. This work was supported by grants from the National Institutes of Health grants GM31655 and GM31657, and the National Institute of Environmental Health Sciences Center grant ESO1896 (to N.R.C. and J.C.). R.K. was a fellow of the Jane Coffin Childs Memorial Fund for Medical Research.

The publication costs of this article were defrayed in part by payment of page charges. This article must therefore be hereby marked "advertisement" in accordance with 18 USC section 1734 solely to indicate this fact.

\section{References}

Adzuma, A. 1992. Stable synapsis of homologous DNA molecules mediated by the $E$. coli RecA protein involves local exchange of DNA strands. Genes \& Dev. 6: 1679-1694.

Bianchi, M. and C.M. Radding. 1983. Insertions, deletions, and mismatches in heterologous DNA made by RecA protein. Cell 35: 511-520.

Bianchi, M., C. DasGupta, and C.M. Radding. 1983. Synapsis and the formation of paranemic joints by $E$. coli RecA protein. Cell 34: 931-939.

Bishop, D.K., D. Park,, L. Xu, and N. Kleckner. 1992. DMC1: A meiosis-specific yeast homolog of E. coli RecA required for recombination, synaptonemal complex formation, and cell cycle progression. Cell 69: 439-456.

Camerini-Otero, R.D. and P. Hsieh. 1993. Parallel DNA triplexes, homologous recombination, and other homology-dependent DNA interactions. Cell 73: 217-223.

Christiansen, G. and J. Griffith. 1986. Visualization of the paranemic joining of homologous DNA molecules catalyzed by the RecA protein of Escherichia coli. Proc. Natl. Acad. Sci. 83: 2066-2070.

Clark, A.J. and A.D. Margulies. 1965. Isolation and characterization of recombination-deficient mutants of $E$. coli $\mathrm{K} 12$. Proc. Natl. Acad. Sci. 53: 451-459.

Cox, M.M. 1993. Relating biochemistry to biology: How the recombinational repair function of RecA protein is manifested in its molecular properties. BioEssays 15: 617-623.

Cox, M.M. and I.R. Lehman. 1981. RecA protein of E. coli pro- 
motes branch migration, a kinetically distinct phase of DNA strand exchange. Proc. Natl. Acad. Sci. 78: 6018-6022.

Cunningham, R.P., C. DasGupta, T. Shibata, and C.M. Radding. 1980. Homologous pairing in genetic recombination: RecA protein makes joint molecules of gapped circular DNA and closed circular DNA. Cell 20: 223-235.

DasGupta, C. and C.M. Radding. 1982. Lower fidelity of RecA protein catalysed homologous pairing with a superhelical substrate. Nature 295: 71-73.

Davis, R.W., M. Simon, and N. Davidson. 1970. Methods Enzymol. 21: 413-428.

Dykstra, C.C., R.K. Hamatake, and A. Sugino. 1990. DNA strand transfer protein $\beta$ from yeast mitotic cells differs from strand transfer protein $\alpha$ from meiotic cells. J. Biol. Chem. 265: 10968-10973.

Dykstra, C.C., K. Kitada, A.B. Clark, R.K. Hamatake, and A. Sugino. 1991. Cloning and characterization of DST2, the gene for DNA strand transfer protein $\beta$ from Saccharomyces cerevisiae. Mol. Cell. Biol. 11: 2583-2592.

Fishel, R., M. Derbyshire, K. Dowjat, C.J. Harris, and S.P. Moore. 1990. Studies on homologous pairing and strand exchange in human cells. In Molecular mechanisms in DNA replication and recombination, (ed. C.C. Richardson and I.R. Lehman) Vol. 127, pp. 343-356. Wiley-Liss, New York.

Halbrook, I. and K. McEntee. 1989. Purification and characterization of a DNA-pairing and strand transfer activitiy from mitotic Saccharomyces cerevisiae. J. Biol. Chem. 264: 21403-21412.

Hamatake, R.K., C.C. Dykstra, and A. Sugino. 1989. Presynapsis and synapsis of DNA promoted by the STP $\alpha$ and singlestranded DNA-binding proteins from Saccharomyces cerevisiae. J. Biol. Chem. 264: 13336-13342.

Heyer, W.D. and R.D. Kolodner. 1989. Purification and characterization of a protein from yeast that binds tightly to singlestranded DNA and simulates a cognate strand exchange protein. Biochemistry 28: 2856-2862.

Heyer, W.-D., D.H. Evans, and R.D. Kolodner. 1988. Renaturization of DNA by a Saccharomyces cerevisiae protein that catalyzes homologous pairing and strand exchange. $J$. Biol. Chem. 263: 15189-15195.

Johnson, A.W. and R. D. Kolodner. 1991. Strand exchange protein 1 from Saccharomyces cerevisiae: A novel multifunctional protein that contains DNA strand exchange and exonuclease activities. J. Biol. Chem. 266: 14046-14054.

Kaguni, J. and D.S. Ray. 1979. Cloning of a functional replication origin of phage G4 into the genome of phage M13.J. Mol. Biol. 135: 863-878.

Kahn, R., R.P. Cunningham, C. DasGupta, and C.M. Radding. 1981. Polarity of heteroduplex formation promoted by $E$. coli recA protein. Proc. Natl. Acad. Sci. 78: 4786-4790.

Kersey, S. and D. Kipling. 1991. Recombination and RNA processing: A common strand? Trends Cell Biol. 1: 110-112.

Kim, J., P.O. Ljungdahl, and G.R. Fink. 1990. kem mutations affect nuclear fusion in Saccharomyces cerevisiae. Genetics 126: $799-812$.

Kipling, D., C. Tambini, and S.E. Kearsey. 1991. rar mutations which increase artificial chromosome stability in Saccharomyces cerevisiae identify transcription and recombination proteins. Nucleic Acids Res. 19: 1385-1391.

Kolodner, R.D., D.H. Evans, and P.T. Morrison. 1987. Purification and characterization of an activity from Saccharomyces cerevisiae that catalyzes homologous pairing and strand exchange. Proc. Natl. Acad. Sci. 84: 5560-5564.

Kowalczykowski, S. 1991. Biochemistry of genetic recombination: Energetics and mechanism of DNA strand exchange. Annu. Rev. Biophys. Chem. 20: 539-575.
Kowalczykowski, S. and A.K. Eggleston. 1994. Homologous pairing and DNA strand exchange proteins. Annu. Rev. Biochem. (in press).

Laban, A. and A. Cohen. 1981. Interplasmidic and intraplasmidic recombination in Escherichia coli K12. Mol. \& Gen. Genet. 184: 200-208.

Larimer, F.W. and A. Stevens. 1990. Disruption of the gene $X R N 1$, coding for a $5^{\prime} \rightarrow 3^{\prime}$ exoribonuclease, restricts yeast cell growth. Gene 95: 85-90.

Little, J.W. and D.W. Mount. 1982. The SOS regulatory system of Escherichia coli. Cell 29: 11-22.

Lowenhaupt, K., M. Sander, C. Hauser, and A. Rich. 1989. Drosophila melanogaster strand transferase. J. Biol. Chem. 264: 20568-20575.

Menetski, J.P., D.G. Bear, and S.C. Kowalczykowski. 1990. Stable DNA heteroduplex formation catalyzed by the Escherichia coli RecA protein in the absence of ATP hydrolysis. Proc. Natl. Acad. Sci. 87: 21-25.

Ogawa, T., X. Yu, A. Shinohara, and E.H. Egelman. 1993. The filament formed by the yeast Rad51 protein has a similar structure to the bacterial RecA filament. Science 259: 18961898.

Radding, C.M. 1991. Helical interactions in homologous pairing and strand exchange driven by RecA protein. J. Biol. Chem. 266: $5355-5358$.

Rao, B.J. and C.M. Radding. 1993. Homologous recognition promoted by RecA protein via non-Watson-Crick bonds between identical DNA strands. Proc. Natl. Acad. Sci. 90: 6646-6650.

Richmond, T.J., J.T. Finch, B. Rushton, D. Rhodes, and A. Klug. 1984. Structure of the nucleosome core particle at $7 \AA$ resolution. Nature 311: 532-537.

Riddles, P.W. and I.R. Lehman. 1985. The formation of paranemic and plectonemic joints between DNA molecules by the recA and single-stranded-DNA binding proteins of Escherichia coli. J. Biol. Chem. 260: 165-169.

Sadowski, P.D. 1993. Site-specific genetic recombination: hops, flips, and flops. FASEB I. 7: 760-767.

Schutte, B.C. and M.M. Cox. 1988. Homology-dependent underwinding of duplex DNA in RecA protein generated paranemic complexes. Biochemistry 27: 7886-7894.

Shinohara, A., H. Ogawa, and T. Ogawa. 1992. Rad51 protein involved in repair and recombination in S. cerevisiae is a RecA-like protein. Cell 69: 457-470.

Sikorav, J.-L. and G.M. Church. 1991. Complementary recognition in condensed DNA: Accelerated DNA renaturation. $J$. Mol. Biol. 222: 1085-1108.

Stark, W.M., M.R. Boocock, and D.J. Sherratt. 1992. Catalysis by site-specific recombinases. Trends Genet. 8: 432-439.

Stevens, A. and M.K. Maupin. 1987. A $5^{\prime} \rightarrow 3^{\prime}$ exoribonuclease of Saccharomyces cerevisiae: Size and novel substrate specificity. Arch. Biochem. Biophys. 252: 339-347.

Story, R.M., D.K. Bishop, N. Kleckner, and T.A. Steitz. 1993. Structural relationship of bacterial RecA proteins to recombination proteins from bacteriophage T4 and yeast. Science 259: $1892-1896$

Sugino, A., J. Nitiss, and M.A. Resnick. 1988. ATP-independent DNA strand transfer catalyzed by protein(s) from meiotic cells of the yeast Saccharomyces cerevisiae. Proc. Natl. Acad. Sci. 85: 3683-3687.

Tishkoff, D.X., A.W. Johnson, and and R.D. Kolodner. 1991. Molecular and genetic analysis of the gene encoding the Saccharomyces cerevisiae strand exchange protein Sep1. Mol. Cell Biol. 11: 2593-2608.

Weinstock, G.M., K. McEntee, and I.R. Lehman. 1979. ATPdependent renaturation of DNA catalyzed by the recA pro- 
Chen et al.

tein of E. coli. Proc. Natl. Acad. Sci. 76: 126-130.

West, S.C. 1992. Enzymes and molecular mechanisms of genetic recombination. Annu. Rev. Biochem. 61: 603-640.

West, S.C., E. Cassuto, and P. Howard-Flanders. 1981. Heteroduplex formation by RecA protein: Polarity of strand exchange. Proc. Natl. Acad. Sci. 78: 6149-6153.

Wu, A.M., M. Bianchi, C. DasGupta, and C.M. Radding 1983. Unwinding associated with synapsis of DNA molecules by RecA protein. Proc. Natl. Acad. Sci. 80: 1256-1260. 


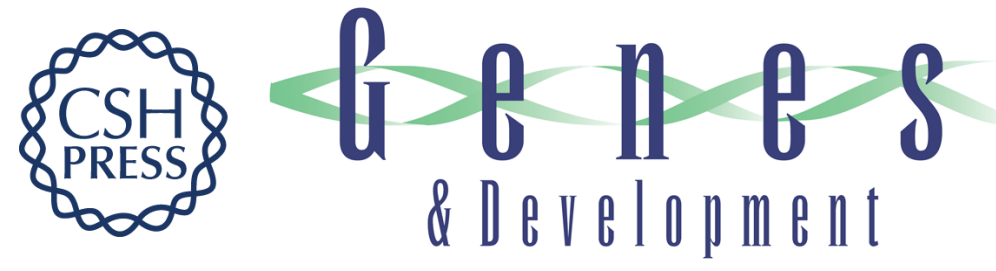

\section{The Sep1 strand exchange protein from Saccharomyces cerevisiae promotes a paranemic joint between homologous DNA molecules.}

J Chen, R Kanaar and N R Cozzarelli

Genes Dev. 1994, 8:

Access the most recent version at doi:10.1101/gad.8.11.1356

References This article cites 49 articles, 25 of which can be accessed free at:

http://genesdev.cshlp.org/content/8/11/1356.full.html\#ref-list-1

License

Email Alerting

Service

Receive free email alerts when new articles cite this article - sign up in the box at the top right corner of the article or click here.

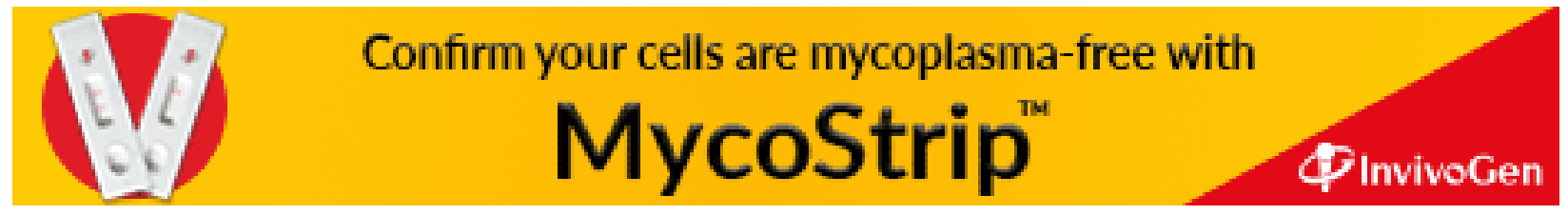

